\title{
CUTTING ENVIRONMENT IMPACT ON THE ALUMINIUM ALLOY MACHINING
}

\author{
Eva BURANSKÁ ${ }^{1}$, Ivan BURANSKÝ ${ }^{2}$, \\ Michaela KRITIKOS ${ }^{2}$, Kristína GERULOVÁ ${ }^{1}$, Ján LÍŠKA ${ }^{3}$ \\ ${ }^{1}$ SLOVAK UNIVERSITY OF TECHNOLOGY IN BRATISLAVA, \\ FACULTY OF MATERIALS SCIENCE AND TECHNOLOGY IN TRNAVA, \\ INSTITUTE OF INTEGRATED SAFETY \\ Ulica JÁNA BOTTU 2781/25, 91724 TRNAVA, SlOVAK REPUBliC \\ ${ }^{2}$ SLOVAK UNIVERSITY OF TECHNOLOGY IN BRATISLAVA, \\ FACULTY OF MATERIALS SCIENCE AND TECHNOLOGY IN TRNAVA, \\ INSTITUTE OF PRODUCTION TECHNOLOGIES, \\ UliCA JÁNA BotTu 2781/25, 91724 TRNAVA, SLOVAK REPUBLIC \\ ${ }^{3}$ JOHN VON NEUMANN UNIVERSITY \\ GAMF FACULTY OF MECHANICAL ENGINEERING AND IT \\ DEPARTMENT OF VEHICLE TECHNOLOGY \\ 6000 KECSKEMÉT, IZSÁKI STR. 10, HUNGARY \\ e-mail: eva.buranska@stuba.sk, ivan.buransky@stuba.sk, michaela.kritikos@stuba.sk, \\ kristina.gerulova@stuba.sk, liska.janos@gamf.uni-neumann.hu \\ Received: 17.04.2019, Accepted: 21.06.2019, Published: 25.07.2019
}

\begin{abstract}
The paper is focused on the experiment where the effects of the cutting environment and feed of drilling on the bores roughness and cylindricity were evaluated. Dry drilling of aluminium alloys (without using cutting fluids) is an environmentally friendly machining process but also an extremely difficult task, which is due to the tendency of aluminium to adhere to the drills made of conventional materials such as high-speed steel; and therefore three cutting environments (namely two different emulsions and compressed air) were used in the experiment. The article demonstrates multicriterial optimization of input factors (cutting environment, feed) for two defined target functions: roughness and cylindricity). The measured values were subjected to mathematico-statistical Analysis of Variance (ANOVA). ANOVA was used for examining the effects of machining parameters and their contribution to the surface roughness and bores cylindricity. The optimal cutting parameters were evaluated for "Smallerthe-Better" quality characteristics of both output responses, as can be seen in our article published previously. Based on the ANOVA, we determined that cutting environment exhibited higher percentage of contribution on bores quality than feed of machining. The results show $77.37 \%$ impact of cutting environment and $8.13 \%$ impact of feed on quality of machined bores.
\end{abstract}




\section{Key words}

Cutting environment, feed, drilling, aluminium alloy

\section{INTRODUCTION}

In recent years, aluminium and its alloys have been considered to be the most widely used non-ferrous metals. Their use keeps increasing yearly owing to their favourable mechanical properties and relatively low weight.

Drilling is one of the most useful metal cutting processes used in various applications, such as aerospace, electronics, and automotive sectors. In traditional drilling methods, the thrust force, torque, tolerance, and tribology (surface roughness) are related to the cutting conditions and tool geometry [2]. Drilling is a very demanding operation since it has certain specifications which differ from milling and turning. The major difference includes a variable cutting speed along the main cutting edge, more difficult chip evacuation and poor access of fluids to the cutting area [3].

During the drilling process of aluminium alloy, certain specifications are different from milling and turning. The major differences comprise: 1 ) a variable cutting speed along the main cutting edge, 2) more difficult chip evacuation, and 3) poor access of liquids into the cutting area. One of the problems is selection of a suitable cutting environment for drilling the aluminium alloy to ensure the required quality of the bore (mainly roughness and cylindricality).

Dry drilling of aluminium alloys (without using cutting fluids) is an environmentally friendly machining process, but also an exceedingly difficult task due to the aluminium tendency to adhere to the drills made of conventional materials such as the high-speed steel [4].

Cutting fluids have been used extensively in deep hole machining operations to achieve the following results: 1) to force the chips back out of the deep hole as it is being drilled or bored; 2) to cool the cutting zone; and 3) to reduce friction and wear [5], [6].

Quality of the machined surface benchmarks the efficiency of machining processes in manufacturing industry [7]. Importance of cutting environment for metal machining keeps growing and posing significant impact on improving the quality of the workpiece surface and tool life, while reducing energy consumption [8].

However, the current environmental and health concerns require from manufacturers to reduce the volume of their waste streams [9]. Dry machining process (i.e. machining without the use of metal removal fluids) satisfies the aforementioned circumstances for steel and other ferrous materials [10], [11] but the dry machining of aluminium and especially the dry drilling of cast Al-Si alloys proved to be difficult due to adhesion of aluminium to the drill.

Therefore, choice of the cooling and cutting materials is an important factor. There is no unanimous opinion, which cutting material is advisable to choose. The most commonly used materials are carbides and diamonds. The adhesive effect is reduced by coating of drills. Our experimental procedure included drilling and subsequent measurement of roughness and cylindricity by changing the cutting environment and feed.

Surface quality is one of the most specified customer requirements, and surface roughness is the major indicator of the workpiece surface quality. Surface roughness is mainly the result of various controllable or uncontrollable process parameters, and it is difficult to achieve and monitor them. A considerable number of studies have examined the effects of cutting speed, feed, depth of cut, nose radius and other factors on the surface roughness [12]. 


\section{MATERIALS AND METHODS}

Our experiment was performed in the Centre of Excellence of 5-Axis Machining at the Faculty of Materials Science and Technology in Trnava, Slovak University of Technology in Bratislava. A computer numerical control (CNC) milling machine centre DMG MORI 85 monoBLOCK was used [1].

A cutting tool (Figure 1) of twist drill $12 \mathrm{~mm}$ in diameter (marking - DH452120-1 produced by YG company) was used. Tool has universal application for bore drilling.

The tool was designed with the possibility of internal lubrication. That means, selected cutting environment was fed into the cutting area of the tool. Three new drills were used for machining operations. Parameters of the tool are shown in Table 1. Table 2 shows chemical composition of $\mathrm{Al}-\mathrm{Mg}-\mathrm{Si}$ alloy, the workpiece material, which is extensively used in the defence and aerospace applications. Table 3 shows the machining parameters.

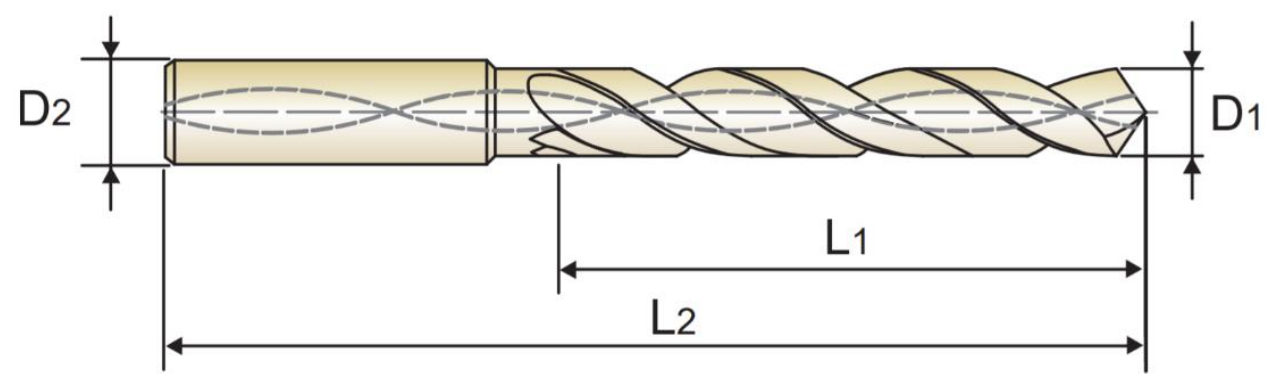

Fig. 1 Twist drill DH452120-1_ TiAlN-coated solid carbide drills [9]

\begin{tabular}{|c|c|c|c|c|c|c|c|c|c|}
\hline $\begin{array}{c}\text { D1 } \\
(\mathbf{m m})\end{array}$ & $\begin{array}{c}\text { D2 } \\
(\mathbf{m m})\end{array}$ & $\begin{array}{c}\mathbf{L 1} \\
(\mathbf{m m})\end{array}$ & $\begin{array}{c}\mathbf{L 2} \\
(\mathbf{m m})\end{array}$ & $\begin{array}{l}\text { Cutting } \\
\text { material }\end{array}$ & Coating & $\begin{array}{l}\mathbf{E r} \\
\left(^{\circ}\right)\end{array}$ & $\begin{array}{c}\alpha \\
\left({ }^{\circ}\right)\end{array}$ & $\begin{array}{c}\gamma \\
\left(^{\circ}\right)\end{array}$ & $\begin{array}{l}\lambda s \\
\left({ }^{\circ}\right)\end{array}$ \\
\hline 2 & 12 & 71 & 118 & $\begin{array}{l}\text { cemented } \\
\text { carbide }\end{array}$ & TiAlN & 140 & 11 & 10 & 35 \\
\hline
\end{tabular}

\begin{tabular}{|l|c|c|c|c|c|c|c|c|}
\hline Table 2 Chemical composition of the workpiece material \\
\hline Alloy & $\mathrm{Al}$ & $\mathrm{Zn}$ & $\mathrm{Cu}$ & $\mathrm{Fe}$ & $\mathrm{Mg}$ & $\mathrm{Si}$ & $\mathrm{Mn}$ & $\mathrm{Ti}$ \\
\hline \% Weight & base & 0.2 & 0.1 & 0.5 & 0.7 & 0.7 & 0.4 & 0.05 \\
\hline
\end{tabular}

\begin{tabular}{|c|c|}
\hline \multicolumn{2}{|c|}{ Table 3 Machining parameters } \\
\hline Parameters & Value \\
\hline Cutting speed & $173 \mathrm{~m} / \mathrm{min}$ \\
\hline Feed 1 & $0.2 \mathrm{~mm}$ \\
\hline Feed 2 & $0.3 \mathrm{~mm}$ \\
\hline Feed 3 & $0.4 \mathrm{~mm}$ \\
\hline
\end{tabular}

For our experiment, three types of cutting environment were selected: 
1. Emulsion $\boldsymbol{A}$ - performance semi-synthetic water-miscible machining liquid without boron, amines, chlorine and substances which release formaldehyde destined for machining of aluminium alloys (5\% emulsion).

2. Emulsion B - synthetic pH neutral coolant designed especially for demanding machining of aluminium and other alloys (manufacturer recommends a minimum, rate amounts to 6\% concentration for all operations, which ensures reliable protection of metal surfaces against corrosion).

3. Compressed air $\boldsymbol{C}$ - with a pressure of $6.5 \mathrm{MPa}$.

The bore surface roughness of AlMgSi1 alloy (ENAW 6082) was measured by the Surtronic 3+ Taylor-Hobson surface roughness tester in three different positions, as shown in Figure 2 at the length of $4 \mathrm{~mm}$. The individual arithmetic mean was calculated for all the measured values for each hole to get one roughness value, resp. the arithmetic mean deviation of the profile for one hole.

The bore cylindricity was measured by Prismo 10 coordinate measurement machine. For the measurement and evaluation of the measured values, we used CALYPSO software. For the evaluation of cylindricity, 1041 points were scanned. The same procedure as in the case of roughness values was used.

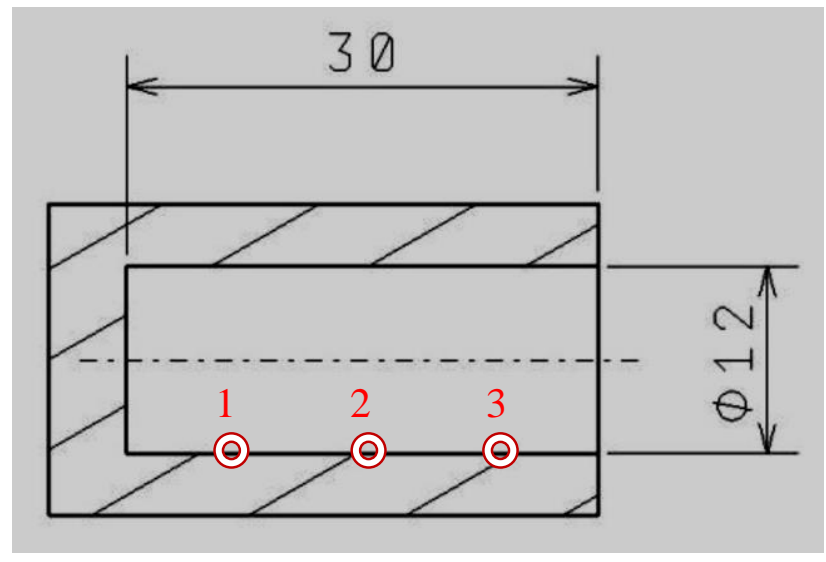

Fig. 2 Three positions for measuring hole surface roughness

To obtain higher accuracy, a full factorial DOE (Design of Experiment) for two factors in three levels was used [13], [14]. Table 4 shows the levels of process factors and their encoding.

\begin{tabular}{|c|c|c|c|c|c|c|c|}
\hline \multirow{3}{*}{$\begin{array}{c}\text { Factor } \\
\text { No. }\end{array}$} & \multirow[t]{3}{*}{ Factor } & \multirow[t]{3}{*}{ Dimension } & \multicolumn{2}{|c|}{ Marking } & \multicolumn{3}{|c|}{ Factor levels } \\
\hline & & & & & Min & Med & Max \\
\hline & & & Original & Coded & -1 & 0 & 1 \\
\hline 1 & Cutting environment & - & & $\mathrm{x}_{1}$ & $\mathrm{~A}$ & $\mathrm{~B}$ & $\mathrm{C}$ \\
\hline 2 & Feed & {$[\mathrm{mm}]$} & $\mathrm{f}$ & $\mathrm{x}_{2}$ & 0.2 & 0.3 & 0.4 \\
\hline
\end{tabular}

Table 5 shows the assignment of the two factors considered in three levels of the L9 orthogonal array with their values. 


\begin{tabular}{|c|c|c|c|c|}
\hline \multicolumn{2}{|c|}{ Table 5 Assignment of the factors with their values } \\
\hline \multirow{2}{*}{ No. of exp. } & \multicolumn{2}{|c|}{ Current experimental conditions } & \multicolumn{2}{c|}{ Measured values } \\
\cline { 2 - 5 } & $\begin{array}{c}\text { Cutting environment } \\
(-)\end{array}$ & $\begin{array}{c}\text { Feed } \\
(\mathbf{m m})\end{array}$ & $\begin{array}{c}\text { Cylindricity } \\
(\mathbf{m m})\end{array}$ & $\begin{array}{c}\text { Ra } \\
(\boldsymbol{\mu m})\end{array}$ \\
\hline 1 & A & 0.2 & 0.022 & 1.49 \\
\hline 2 & A & 0.3 & 0.012 & 1.62 \\
\hline 3 & A & 0.4 & 0.012 & 1.83 \\
\hline 4 & B & 0.2 & 0.029 & 2.28 \\
\hline 5 & B & 0.3 & 0.011 & 2.05 \\
\hline 6 & B & 0.4 & 0.011 & 2.18 \\
\hline 7 & C & 0.2 & 0.012 & 1.25 \\
\hline 8 & C & 0.4 & 0,014 & 1.37 \\
\hline 9 & C & & 0.015 & 1.59 \\
\hline
\end{tabular}

\section{RESULT AND DISCUSSION ON RESULTS}

One of the ways of analysing and evaluating the results of the experiment, with respect to the multi-criteria optimization is to use methods of Desirability Function Analysis = DFA. The optimization method consists in defining the non-dimensional value called suitability coefficient $(\mathrm{dG})$, while its margin expresses the interval $\langle 0 ; 1\rangle$. The application of this method as well as the related results are published in our previous article [1].

Analysis of Variance (ANOVA) is a technique that allows considering various sources of variability in data. When measurements are repeated, there are always some deviations. These random deviations may cause that the significance of the differences between groups of repeated measurement will be more difficult to establish [15].

The basic idea of ANOVA in this case is whether and how it may be statistically identified when divided into groups in the set of results of parallel determinations. The total variance of the summary data is the combination of variance between the groups and within the groups. ANOVA allows separating the different sources of variance and comparing partial variances mutually in order to determine whether the differences between them were statistically significant. Respectively, providing the answer to the question of whether different groups are representing selections from one basic set [16].

The principle of the ANOVA lies in decomposition of the total variance (Sum of Squares Total $=$ SST), which is expressed in sums of squares, to the intergroup, that is explained by the group (Sum of Squares Between $=$ SSB), and the intragroup, thus an error (Sum of Squares Error $=$ SSE) [17].

Analysing of the experiment is based on the obtained values, where the result is illustrated by the analysis of desirability. Specifically, it uses the value of comprehensive suitability indices from Table 5.

Table 6 comprises the results, which were obtained by application of the previous formulas and calculations in the experiment.

\begin{tabular}{|l|l|r|l|}
\hline \multicolumn{4}{|l|}{ Table 6 Outputs of ANOVA } \\
\hline Variability source & SSB (-) & $\mathrm{Pi}(\%)$ & F-criterion \\
\hline Cutting environment & 0.542 & 77.37 & 10.67 \\
\hline Feed & 0.057 & 8.13 & 1.12 \\
\hline Error (SSE) & 0.102 & 14.50 & - \\
\hline Sum (SSC) & 0.699 & 100.00 & - \\
\hline
\end{tabular}


The obtained values indicate that the cutting environment has the significant impact on the surface roughness and cylindricity of the pattern. The percentage value of this factor is $77.37 \%$. Using a suitably chosen cutting environment it is therefore possible to reduce the roughness and cylindricity values, which also leads to the actual improvement in the quality of the drilled bores. On the contrary, the percentage value of the impact of the feed factor is evaluated on the level of $8.13 \%$, suggesting that changes of the feed settings for a given process do not significantly affect the evaluated characteristics.

We cannot omit the percentage impact in the case of intragroup, resp. error variability with a value of $14.5 \%$. This value represents the fact that the process was also influenced by other phenomena which were not dealt with in this experiment, resp. were not under investigation, e.g. the impact of tool wear, quality of the sharpened tool, geometry and so on.

If evaluating test results by the test criteria it can be argued that a significant influence on the observed target function is just cutting environment. This argument reflects the fact that the calculated F comparative criterion for the cutting environment takes the value 10.67, which is greater than the tabulated value (6.94).

Therefore, it is possible to speak of the statistical significance of the mentioned input factor. Conversely, if the results of the test criterion for feed (1.12) are compared with the tabulated value of F-criterion (6.94), it can be argued that the input parameter is not statistically significant in the evaluation of target functions. And it is precisely because the calculated value is less than the tabulated value of F-test criteria.

\section{CONCLUSION}

The aim of the paper was to evaluate the influence of cutting environment and feed of drilling on the bores roughness and cylindricity. The multicriteria optimization of input factors (cutting environment, feed) following two defined functions (roughness and cylindricity) was demonstrated. Based on the ANOVA, it was comfirmed that contribution of cutting environment on bores quality is higher than that of feed of drilling. The results show $77.37 \%$ impact of cutting environment and $8.13 \%$ impact of feed on quality of machined bores. Using appropriately selected cutting environment, it is thus possible to reduce the roughness and cylindricity values, which also leads to the actual increase in the quality of the machined bores.

In future research, authors are going to focus on investigation of the cutting environment effects on the cutting edge microgeometry during the machining of difficult materials, such as Inconel super-alloy and stainless steel. Authors are also going to determine the influence of edge preparation on the tool life of cemented carbide drilling cutters and cemented carbide milling cutters.

\section{Acknowledgements}

The article was written with the support of the Project of the VEGA grant agency of the Ministry of Education, Science, Research and Sport of the Slovak Republic and the Slovak Academy of Sciences, No. 1/0097/17: "The Research of Novel Method for Cutting Edge Preparation to Increase the Tool Performance in Machining of Difficult-to-Machine Materials", and APVV project of Slovak Research and development Agency of the Ministry of Education, Science, Research and Sport of the Slovak Republic, No. APVV-16-0057: "Research into the Unique Method for Treatment of Cutting Edge Microgeometry by Plasma Discharges in Electrolyte to Increase the Tool Life of Cutting Tools in Machining of Difficult-to-Machine Materials." 


\section{References}

[1] BURANSKÁ E., BURANSKÝ, I. 2018. Cutting Environment Impact on the Aluminium Alloy Machining (DFA). In: 29th DAAAM International Symposium, pp. 1158-1163.

[2] GHASEMI, A. H., KHORASANI, A. M., GIBSON I. 2018. Investigation on the effect of a precenter drill hole and tool material on thrust force, surface roughness, and cylindricity in the drilling of Al7075. Materials (Basel)., 11(1).

[3] Dańa, M., Zetek, M., Schorník,V. 2015. Effect of cutting edge geometry on cutting tool life when drilling inconel 718. In: Ann. DAAAM Proc. Int. DAAAM Symp., Vol. 2015-Janua, No. 2016, pp. 709-714, 2015.

[4] BHOWMICK, S., ALPAS, A. T. 2008. Minimum quantity lubrication drilling of aluminiumsilicon alloys in water using diamond-like carbon coated drills. Int. J. Mach. Tools Manuf., Vol. 48(12-13), pp. 1429-1443.

[5] YU, D. G. 2017. Deep hole drill with positive taper and principle for elimination of drill deviation using cutting fluid. Int. J. Adv. Manuf. Technol., 89(9-12), pp. 3195-3206.

[6] KONG,L., LI, Y., LV, Y., WANG, Q. 2013. Numerical investigation on dynamic characteristics of drilling shaft in deep hole drilling influenced by minimal quantity lubrication. Nonlinear Dyn., 74(4), pp. 943-955.

[7] RAPETI, P., PASAM, V. K., RAO GURRAM, K. M., REVURU, R. S. 2018. Performance evaluation of vegetable oil based nano cutting fluids in machining using grey relational analysis-A step towards sustainable manufacturing. J. Clean. Prod., 172, pp. 2862-2875.

[8] KRÁLIK, M., BACHRATÝ, M., POKUSOVÁ, M., DURAKBASA, N. M. 2017. Measuring of friction factor of cutting environment. Ann. DAAAM Proc. Int. DAAAM Symp., pp. 118-123.

[9] YG. Inox carbide drill long with coolant holes for Stainless Steel (5xD)-Metric [online]. YG-1: www.yglusa.com

[10] KONCA, E., CHENG,Y. T., WEINER, A. M., DASCH, J. M., ERDEMIR, A., ALPAS, A. T. 2005. Transfer of $319 \mathrm{Al}$ alloy to titanium diboride and titanium nitride based (TiAlN, TiCN, TiN) coatings: Effects of sliding speed, temperature and environment. Surf. Coatings Technol., 200(7), pp. 2260-2270.

[11] KLOCKE, F., EISENBLÄTTER, G. 1998. Dry cutting - State of research. VDI Berichte, 46(1399), pp. 159-188.

[12] ZHUJANI, F., QEHAJA, N., ABDULlAHU, F., BRUQI, M. 2016. Mathematical Modelling of Surface Roughness for Evaluating the Effects of Cutting Parameters in Drilling Process. Ann. DAAAM Proc. Int. DAAAM Symp., pp. 0195-0202.

[13] CHEN, H., CHANG, S., TANG, C. 2017. Application of the Taguchi Method for Optimizing the Process Parameters of Producing Lightweight Aggregates by Incorporating Tile Grinding Sludge with Reservoir Sediments. Materials (Basel)., 10(11), p. 16.

[14] GAAZ,T. S., SULONG, A. B. A., KADHUM, A. H., NASSIR, M. H. 2016. Optimizing Injection Molding Parameters of Different Halloysites Type-Reinforced Thermoplastic. Materials (Basel)., 9(11), p. 19.

[15] BURANSKÁ, E., GERULOVÁ, K., BURANSKÝ, I. 2016. Influence of cutting environment on tool life. Res. Pap., 24(38), pp. 9-15.

[16] DOHNAL, L. 1999. Kapitola VII. ANALYSA ROZPTYLU - ANOVA. In: Št Satistical method for clinical epidemiology and laboratory, Spring, pp. 37-42.

[17] RIMANČÍK, M. 2007. Statistic for practice. First Edition.

\section{ORCID}

Eva Buranská

Ivan Buranský

Michaela Kritikos

Kristína Gerulová
0000-0002-2382-7508

0000-0002-7600-9007

0000-0001-5406-3953

0000-0003-2588-8627 